\title{
Fútbol callejero: nascido e criado no Sul
}

Fútbol Callejero: Born and Raised in the South

Fútbol callejero: né et créé dans le Sud

\section{Maurício Mendes Belmonte e Luiz Gonçalves Junior}

\section{OpenEdition}

\section{Journals}

Edição electrónica

URL: http://journals.openedition.org/rccs/7403

DOI: $10.4000 /$ rccs.7403

ISSN: 2182-7435

\section{Editora}

Centro de Estudos Sociais da Universidade de Coimbra

\section{Edição impressa}

Data de publição: 1 setembro 2018

Paginação: 155-178

ISSN: 0254-1106

\section{Refêrencia eletrónica}

Maurício Mendes Belmonte e Luiz Gonçalves Junior, « Fútbol callejero: nascido e criado no Sul », Revista Crítica de Ciências Sociais [Online], 116 | 2018, posto online no dia 31 julho 2018, consultado o 12 setembro 2020. URL : http://journals.openedition.org/rccs/7403 ; DOI : https://doi.org/10.4000/ rccs.7403

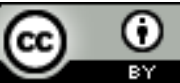




\section{MAURÍCIO MENDES BELMONTE, LUIZ GONÇALVES JUNIOR}

\section{Fútbol callejero: nascido e criado no Sul}

O objetivo deste artigo é identificar, descrever e compreender processos educativos decorrentes de uma sistematização de experiência com a prática social do fútbol callejero, desenvolvido em um projeto socioeducativo numa comunidade socioeconomicamente vulnerável. Na trajetória metodológica, optamos pela postura fenomenológica em interface com a sistematização de experiências tendo como premissa a ética de investigar com outrem. Da análise dos dados emergiu a categoria "Fútbol callejero é para ser mais!", revelando ações/atitudes de cuidado com outrem, corresponsabilidade, autonomia e protagonismo dos/as participantes. Consideramos a necessidade de busca de novos horizontes em práticas e futebóis historicamente invisibilizados (motricidades ausentes), que vivem, lutam, resistem, se manifestam enquanto motricidades emergentes nas periferias das cidades.

Palavras-chave: educação popular; epistemologias do Sul; futebol de rua; processos educativos; valores éticos.

\section{Introdução}

Há cinco mil anos, os malabaristas chineses faziam dançar a bola com os pés, e foi na China que tempos depois se organizaram os primeiros jogos. A meta ficava no centro e os jogadores evitavam, sem usar as mãos, que a bola tocasse no chão. [...] Sabe-se que em tempos antigos os egípcios e os japoneses se divertiam chutando a bola. No mármore de uma tumba grega de cinco séculos antes de Cristo, aparece um homem fazendo embaixadas com a bola no joelho. (Galeano, 2014: 25)

Na sociedade contemporânea, compreendemos o desporto futebol como um fenômeno sociocultural, que se configura como uma prática social que atinge, direta ou indiretamente, bilhões de pessoas no mundo inteiro. Também se apresenta como o desporto mais globalizado na atualidade, tendo alcançado o espantoso número de 3,5 mil milhões de espectadores/ /as durante a Copa do Mundo, realizada no Brasil, no ano de 2014 (Nolasco, 2015: 492). 
Não raramente encontramos a atribuição de origem inglesa ao desporto futebol, cabe-nos ressaltar, porém, que o futebol ou mesmo o críquete e o tênis não foram criações sui generis da Inglaterra do século XVIII. O mérito dos ingleses foi a codificação das regras e a expansão do futebol e outros desportos para demais países europeus e, posteriormente, para países de outros continentes, difundindo a maneira hegemônica de se praticar o futebol na atualidade (Galeano, 2014; Nolasco, 2015), a saber: predominantemente competitiva.

O desenvolvimento do desporto no contexto inglês guarda estreita relação com a Revolução Industrial: de um lado pela necessidade da indústria nascente ter mão de obra melhor; de outro lado, pelas conquistas sociais dos/as trabalhadores/as, como redução da jornada de trabalho, tornando o desporto mais acessível, quer seja no espaço escolar, quer seja no tempo disponível ampliado (fora do tempo de trabalho), inclusive na realização de certames desportivos em espaços escolares e junto aos grêmios operários. Neste cenário, o futebol poderia ocupar o tempo ocioso dos trabalhadores afastando-os de atividades nocivas (do ponto de vista do patronato), como as discussões políticas nos pubs e sindicatos (Grifi, 1989).

Entretanto, conforme sugere a epígrafe que abre este artigo, práticas semelhantes ao desporto futebol que é hegemonicamente difundido e praticado, foram (re)criadas e (re)significadas inúmeras vezes por diversos povos, regiões e períodos históricos, guardando distintas intencionalidades, regras e modos de jogar. Voltando a atenção para a sociedade hodierna, muito mais do que exclusivamente um desporto competitivo, o futebol pode ser entendido enquanto prática social com intencionalidades diferenciadas nos contextos históricos e sociais em que o encontramos, pois ao mesmo tempo que observamos guerras de torcidas, interesses de patrocinadores, de corporações, de chefes de Estado, o uso de doping, fraudes e corrupção, também encontramos aqueles/as que o praticam pela alegria de brincar/ /jogar, por melhorias da condição de saúde, motivação espiritual, sociabilidade, integração e cooperação.

Ressaltamos que o futebol à inglesa e as práticas ancestrais a ele ligadas têm um sentido peculiar ao lócus em que foi gerado e praticado, de tal modo que se retirarmos a Motricidade Humana ${ }^{1}$ de seu contexto ela perderá completamente o seu significado. Portanto, não pretende este artigo

\footnotetext{
${ }^{1}$ A Motricidade Humana compreende o ser como intencionalidade, que se dirige a outrem, às coisas com os quais compartilha o mundo. Este "ser-aí" (Dasein) é intramundano, é lançado ao mundo e não pode ser desconectado deste e dos outros seres humanos, portanto está sempre sendo-com-outrem-no-mundo. Ser que se realiza e se compreende na, e a partir da, experiência com outrem em contexto do mundo. Para saber mais, consultar Sérgio (2003), Merleau-Ponty (2011).
} 
uma comparação de práticas do futebol do passado com as do presente, mas o reconhecimento de que há, através dos tempos, diferentes práticas de futebol, e que, decorrente de fatores históricos, políticos, sociais, espirituais e econômicos, na contemporaneidade temos um futebol hegemônico (altamente visibilizado) e futebóis não hegemônicos (invisibilizados).

Deste modo, embora haja hegemonia da prática de futebol à inglesa, decorrente da codificação das regras e expansão das mesmas através de campeonatos e torneios mundo afora, sobretudo via meios de comunicação de massa, facilmente ainda encontramos diferentes maneiras de se jogar o futebol, ou como intencionalmente preferimos denominar futebóis (no plural), especialmente nas periferias populares das cidades, onde crianças, jovens e adultos/as brincam e jogam futebóis com distintas características: espaços (em campos de terra batida, centros comunitários, pátios de escolas e igrejas, gramados de praças e parques, ruas menos transitadas por automóveis); implementos (bola feita de meia, papéis amassados, garrafas plásticas e/ou suas tampas, entre outros); representações de traves (pedras, estacas, postes de luz, portões, chinelos, entre outros); dimensões do campo (de acordo com a disponibilidade); regras (inclusive criadas pelos participantes no momento do jogo); número de jogadores (conforme interessados na prática, podendo inclusive serem as equipes mistas, com homens e mulheres ao mesmo tempo); ou seja, um sem-fim de possibilidades.

Nosso argumento é de que práticas do Sul (metafórico e geográfico) têm sido insistente e ideologicamente invisibilizadas, tornadas ausentes. Inspirando-nos na sociologia das ausências e das emergências de Santos (2002: 246), buscamos "transformar objetos impossíveis em possíveis e com base neles transformar as ausências em presenças" ou emergências. Em analogia, transformar motricidades ausentes em motricidades emergentes. Com efeito, neste artigo privilegiaremos a investigação de uma prática do Sul (o fútbol callejero, originário da Argentina) com povos do Sul (participantes do projeto socioeducativo VADL-MQF - Vivências em Atividades Diversificadas de Lazer - Mais que Futebol, que se desenvolve no Brasil) e não sobre ou para tais povos, conforme preconizam as epistemologias do Sul propostas por Santos e Meneses, que são compreendidas

metaforicamente como um campo de desafios epistêmicos, que procuram reparar os danos e impactos historicamente causados pelo capitalismo na sua relação colonial com o mundo. [...] A ideia central é [...] que o colonialismo [...] foi também uma dominação epistemológica, uma relação extremamente desigual de saber-poder que conduziu à supressão de muitas formas de saber próprias dos povos e/ou nações 
colonizados. As epistemologias do Sul são o conjunto de intervenções epistemológicas que denunciam essa supressão, valorizam os saberes que resistiram com êxito e investigam as condições de um diálogo horizontal entre conhecimentos. (2009: 12-13)

Entendemos que tais aprendizados podem evitar o "desperdício de experiência” (Santos, 2009), de modos de vida e de conhecimentos, ora por força da razão indolente, preguiçosa, acomodada e desesperançada, ora por força de uma supervalorização do conhecimento científico moderno, eurocêntrico, do Norte. Também se referem as epistemologias do Sul a uma crítica, um desmascaramento e superação de três grandes formas de opressão: colonialismo, capitalismo e patriarcado.

Com tais premissas, destacamos que o objetivo central deste artigo é identificar, descrever e compreender os processos educativos decorrentes de uma sistematização de experiência com a prática social do fútbol callejero que é desenvolvida no projeto socioeducativo VADL-MQF junto a crianças e adolescentes moradoras/es de bairros periféricos e empobrecidos da cidade de São Carlos, interior do estado de São Paulo, Brasil.

Em nosso entender, e na esteira de Oliveira et al., as práticas sociais

decorrem de e geram interações entre os indivíduos e entre eles e os ambientes [...] em que vivem. Desenvolvem-se no interior de grupos, de instituições, com o propósito de produzir bens, transmitir valores, significados, ensinar a viver e a controlar o viver; enfim, manter a sobrevivência material e simbólica das sociedades humanas. (2014: 33)

Oliveira et al. acrescentam que as práticas sociais podem abrigar tensões decorrentes de um "convívio amistoso, tenso, acolhedor, excludente" no qual "as pessoas se educam na sua humanidade para a cidadania negada, conquistada, assumida” (2014: 35).

Com relação aos processos educativos, estes estão presentes em todas as práticas sociais e as pessoas que delas participam relacionam suas aprendizagens com aquelas advindas de outras práticas sociais, ou seja, elas interconectam os conhecimentos adquiridos em casa, na escola, no bairro, na igreja, nos centros sociais, nas praças, nos parques, nas ruas e nos demais tempos-espaços com suas novas experiências de aprendizagens (Oliveira et al., 2014). Assim, conforme proposto por Gonçalves Junior, Carmo e Corrêa, compreendemos que os processos educativos pressupõem o "diálogo equitativo e a intencionalidade dirigida para a cooperação, superação, o ser mais, demandando autonomia, possibilidade de decisão e de transformação" (2015: 176), possibilitando a cada um e a cada uma "refletir criticamente 
sobre sua própria condição de pertencimento ao mundo com os outros, educando e educando-se, tornando-se pessoa" (ibidem: 177).

Com o intuito de situar os/as leitores/as acerca do fútbol callejero, trazendo-o para o bojo das discussões científico-políticas, descreveremos no tópico seguinte sua origem e metodologia. Posteriormente apresentaremos o projeto socioeducativo VADL-MQF, contexto no qual foi desenvolvida uma investigação que deu origem a este artigo, seguido pela descrição do método de sistematização de experiências em interfaces com a fenomenologia, momento em que detalhamos os procedimentos de pesquisa, resultados e considerações.

\section{Do texto ao contexto: o ethos de surgimento do método fútbol callejero} Ao situar as origens do fútbol callejero, encontramos a história de sua criação no sul geográfico e epistemológico, a saber, por jovens latino-americanos com idade entre 14 e 15 anos, acompanhados pelo ex-jogador de futebol semiprofissional Fabián Ferraro, junto ao Club Atlético Defensores del Chaco, em Moreno, bairro periférico e empobrecido da área metropolitana de Buenos Aires, Argentina.

Os jovens que representavam a equipe de Moreno residiam em um complexo de bairros que formavam Paso del Rey, território também formado pelos bairros Malvinas Argentina, Chaco Chico e José C. Paz, configurando-se uma zona de alta vulnerabilidade socioeconômica, conforme descrito por Artavia-Loría:

$45 \%$ da população vivem abaixo da linha da pobreza; $17 \%$ vivem na indigência e $30 \%$ sofrem com o desemprego e subemprego.

A zona é conhecida como Paso del Rey. Entre os bairros da zona se encontra o bairro Chaco Chico, assim chamado em função da alta incidência de imigrantes paraguaios que ali moram.

Paso del Rey, com mais de 250.000 habitantes, dispõe de apenas três escolas e nenhuma creche ou pré-escola. (2008: 16)

Artavia-Loría (2008) e Coon e Durbin (2013) descrevem que, em 1994, o Club Atlético Defensores del Chaco, treinado por Fabián Ferraro, sagrou-se campeão do Torneio Provincial de Buenos Aires. Desta feita, 12 adolescentes que compunham a equipe, acompanhados por Fabián Ferraro e pelo educador popular Júlio Jiménez, iniciaram uma luta pela construção de um campo de treinamento elegendo um terreno no bairro de Moreno que era irregularmente utilizado como um depósito de lixo. Após esta eleição, os adolescentes iniciaram uma campanha para arrecadação de donativos para sua aquisição legal. 
Coon e Durbin (2013) afirmam que os adolescentes foram inicialmente desencorajados por parte da população, que chegou a ironizar o projeto. Contudo, o proprietário do terreno se mostrou lisonjeado e surpreso com a atitude dos jovens que lhe fizeram uma oferta e, uma vez que o dono já havia considerado a perda/invasão de sua propriedade, aceitou a proposta deles, efetivando a venda.

Após a compra do terreno foi necessário transformar o depósito de lixo em um campo de futebol. Outra vez, a sagacidade dos adolescentes foi fundamental para a concretização do projeto, posto que ao perceberem a movimentação de caminhões que retiravam terra de um local próximo a Moreno solicitaram aos respectivos motoristas para que depositassem todo aquele material no terreno recém-adquirido por eles (Coon e Durbin, 2013), dando forma e surgimento ao campo de treinamento do Club Atlético Defensores del Chaco, que, naquela época, se tratava de um campo de terra batida.

Neste espaço de treinamento, em meados de 1999, foi edificada a Fundación Defensores del Chaco, contando com investimentos governamentais e privados que possibilitaram a constituição de dois campos de futebol, quadra poliesportiva, teatro comunitário, centro de computação e uma escola de educação infantil. Como se vê, ampliaram a atuação para além da prática do futebol.

Coon e Durbin (2013) consideram ainda que Fabián Ferraro percebeu que alguns/mas jovens, mesmo com a ampliação da oferta de atividades, não frequentavam o espaço recém-construído. De maneira particular, os/as jovens com menor aptidão/habilidade para a prática de futebol, rapazes e moças com envolvimento em gangues e, especialmente, muitas garotas do território eram os/as que não participavam das atividades dentro da citada Fundação. Contudo, o educador ficou intrigado ao observar que estes grupos de jovens que compunham as gangues, geralmente violentos/as e/ou agressivos/as, não se envolviam em brigas nas ocasiões de realização de jogos de futebol organizados e desenvolvidos por eles próprios nas canchas/ /nos campos improvisados. Outra observação apontava que muitas moças participavam dos jogos apenas como espectadoras, acompanhando seus companheiros jogadores.

Diante deste fenômeno, Fabián Ferraro decidiu incentivar e promover mais encontros para a realização destes jogos (autogestionários e extramuros da Fundação), que culminaram com a sistematização do método que passou a ser conhecido como fútbol callejero. A escolha pela prática do futebol se justificou pelo grande potencial que esta modalidade possui para atrair e vincular os/as participantes para experiências que contemplam seus gostos e interesses, posto que nas palavras de Rossini et al.: 
Nestes tempos em que as juventudes são desvalorizadas e deslegitimadas cada vez mais pelos discursos hegemônicos, interpelados quase exclusivamente como consumidores ou usuários e raramente como cidadãos, o fútbol callejero os/as convida para recuperar sua voz, reconhecer seu potencial e protagonizar suas vidas a partir de uma perspectiva emancipadora. O fútbol callejero convida os jovens a serem cidadãos de suas comunidades e do mundo, a se contraporem à exclusão e à injustiça. E nos convida, a todos e todas, a lutar por nosso direito a viver uma vida digna. (2012: 15; tradução dos autores)

Lançando mão de seu status de liderança, Fábian Ferraro propôs o desenvolvimento de partidas de futebol, que passou a denominar fútbol callejero, disputadas por equipes mistas (homens e mulheres jogando juntos/as), envolvendo promoção de atitudes e valores que, de acordo com Rossini et al. (2012), se consolidaram como os três pilares fundamentais do método, a saber:

- Respeito: a outrem e aos acordos e regras combinados pelos/as participantes durante toda a prática;

- Cooperação: entre todos e todas participantes da prática, em oportunidades equitativas de receber a bola, de participar das jogadas, de se engajarem no ataque e/ou na defesa, enfim, de plenamente jogar;

- Solidariedade: ações empreendidas na tentativa de tornar o jogo mais justo e equilibrado, dirimindo as diferenças e contribuindo com o bom andamento da partida.

Outra especificidade do método fútbol callejero reside na organização das partidas disputadas em três tempos. Assim, no 1. ${ }^{\circ}$ tempo, jogadores e jogadoras que irão participar formam um círculo para estabelecer acordos referentes às regras do jogo. Neste momento, o mediador ou mediadora (pessoa que é uma referência reconhecida pelo grupo) toma nota das regras e acordos firmados pelos/as participantes (Rossini et al., 2012).

Após combinar as regras, é iniciado o $2{ }^{\circ}$ tempo, balizado pelos acordos estabelecidos no momento anterior. Durante o $2 .^{\circ}$ tempo, o mediador ou mediadora deverá observar atentamente o jogo e, sempre que necessário, fazer anotações de eventos que tenham relação direta com as regras combinadas e que foram estabelecidas para a partida.

Transcorrido o $2 .^{\circ}$ tempo, é formado um novo círculo e iniciado o 3. ${ }^{\circ}$ tempo, comumente denominado mediação. Esta é iniciada a partir da transformação do número de gols em pontos, sob uma premissa de que a equipe que mais converteu gols inicia a mediação com 2 pontos, enquanto a equipe que menos converteu gols inicia com 1 ponto.

Em continuidade, o/a mediador/a: problematiza situações ocorridas nos momentos anteriores (1. ${ }^{\circ}$ e $2 .^{\circ}$ tempo); consulta os/as jogadores/as acerca 
da manifestação do respeito (ou não) para com outrem, sendo outrem da mesma equipe ou da equipe adversária; consulta os/as participantes acerca do respeito (ou não) para com as regras e acordos previamente estabelecidos; consulta os/as jogadores/as acerca das atitudes que possuem relação com cada um dos pilares do método (respeito, cooperação e solidariedade), os quais também geram pontos. ${ }^{2} \mathrm{O}$ término da partida é marcado pelo consenso entre os/as participantes acerca do resultado final e firmado, geralmente, com aplausos (Rossini et al., 2012).

A dinâmica metodológica do fútbol callejero apresentada até aqui foi propagada para além do contexto argentino. Sánchez e Salermo (2012) comentam que em 2005 foi organizado o primeiro encontro sul-americano de fútbol callejero, em Buenos Aires, e neste encontro a metodologia começou a extrapolar os limites geográficos da Argentina e da América do Sul, passando a ser desenvolvida em países dos continentes africano, europeu e americano.

Ainda em 2005, a Fundación Defensores del Chaco, passou a dedicar-se exclusivamente às ações que eram desenvolvidas apenas no território de Moreno, transferindo a gestão do fútbol callejero para a Fundación Fútbol para el Desarrolo (FUDe), de Buenos Aires, Argentina. Sob sua supervisão, e em parceria com a organização Fédération Internationale de Football Association (FIFA), foram organizados dois campeonatos mundiais de fútbol callejero que ocorreram concomitantemente com a Copa do Mundo, torneio de futebol já amplamente difundido. Foram eles: em 2006 na Alemanha e em 2010 na África do Sul. Tais eventos destinados para a prática do fútbol callejero contaram, inclusive, com aporte financeiro da FIFA.

As experiências de organização de dois mundiais em parceria com a FIFA foram suficientes para a FUDe perceber a necessidade de rompimento com aquela organização que possui poderes globais, uma vez que as intencionalidades da FUDe eram antagônicas à lógica capitalista materializada no apelo e na ideologia comercial impostos pela FIFA. Tal rompimento impulsionou a criação do Movimiento de Fútbol Callejero ${ }^{3}$ no ano de 2012.

Ainda em 2012, a metodologia fútbol callejero aportou no Brasil através da Universidade do Vale do Rio dos Sinos (UNISINOS/RS-Brasil), por meio do Programa de Esporte Integral (PEI) e da associação civil Ação Educativa, Assessoria, Pesquisa e Informação (doravente Ação Educativa). Esta, por sua vez, tem trabalhado para o estabelecimento de polos de desenvolvimento do

\footnotetext{
${ }^{2}$ A valoração atribuída a cada um dos pilares do fútbol callejero está condicionada ao contexto, gostos e interesses de seus/suas praticantes.

3 A Carta de Princípios do Movimiento de Fútbol Callejero, de 2013, encontra-se disponível em http://movimientodefutbolcallejero.org/movimiento/carta-de-principios/. Consultada a 24.05.2017.
} 
fútbol callejero na região da grande São Paulo e algumas cidades do interior deste estado, como o caso de São Carlos e Limeira.

A FUDe e a Ação Educativa encabeçaram, no ano de 2014, a organização do $1{ }^{\circ}$ Mundial de Futebol de Rua, desenvolvido paralelamente à Copa do Mundo, organizada pela FIFA. Porém, desta vez, sem vínculos políticos ou relações financeiras com tal organização. O evento ocorreu em julho de 2014, sendo sediado na cidade de São Paulo e contando com amplo apoio da gestão municipal e a participação de aproximadamente 300 jovens representantes de delegações de 20 países onde se desenvolveu essa metodologia. Este mundial teve caráter alternativo ao futebol comercial e midiático organizado pela FIFA. Na ocasião, foram montadas arenas desportivas para promover o acesso facilitado e gratuito à população interessada em acompanhar os jogos e torcer pelas equipes.

Nós, autores deste artigo, tivemos o primeiro contato com a dinâmica metodológica do fútbol callejero em dezembro de 2013 devido à nossa participação na IV Conferência Latino-Americana de Futebol e Desenvolvimento, realizada na cidade de São Paulo, Brasil, e organizada pela FUDe e pela Ação Educativa. Nesta ocasião, fomos convidados por Fabián Ferraro e por Rodrigo Medeiros, respectivos coordenadores das citadas organizações, para desenvolver a prática do fútbol callejero em São Carlos, de modo a incrementar as ações do projeto socioeducativo VADL-MQF (que será apresentado logo adiante), culminando com a formação do primeiro polo do interior do estado de São Paulo.

Passaremos agora para uma apresentação mais detida do citado projeto, de modo a situar o contexto no qual desenvolvemos a investigação que deu origem ao presente artigo e que nos permitiu anunciar o fútbol callejero como uma prática social que está em consonância com os horizontes das epistemologias do Sul.

\section{O fútbol callejero no projeto socioeducativo: o exercício de ecologia de saberes}

O projeto socioeducativo que trazemos para o debate político-epistemológico tem suas origens no ano de 1999, ocasião em que fora conhecido apenas por Vivências em Atividades Diversificadas de Lazer (VADL), sendo uma das ações do Programa Esporte para a Cidadania, do Departamento de Educação Física e Motricidade Humana (DEFMH) da Universidade Federal de São Carlos (UFSCar). Após atuação em diferentes contextos, ${ }^{4}$

\footnotetext{
${ }^{4}$ Belmonte (2014) faz uma rigorosa descrição da trajetória do projeto socioeducativo. Aqui, nos limitamos a apresentá-lo a partir do ano de 2013, momento em que é estabelecida nova parceria e o fútbol callejero passou a compor as vivências do projeto.
} 
sua equipe de educadores e educadoras foi convidada, no ano de 2013, para iniciar uma parceria junto da Associação Desportiva, Educacional e Social dos Metalúrgicos de São Carlos (ADESM).

Cumpre destacar que a citada associação já desenvolvia atividades de formação desportiva de crianças, adolescentes e jovens para a prática de futebol de alta performance, visando a formação de atletas nesta modalidade. Contudo, almejando aprofundar o caráter educacional da associação, membros da diretoria da ADESM criaram o projeto Mais que Futebol (MQF), culminando no convite à equipe do VADL para compor uma parceria, consolidando, em agosto de 2013, o Vivências em Atividades Diversificadas de Lazer - Mais que Futebol (doravante VADL-MQF), que passou a contar com apoio da Fondation Terre des Hommes (Tdh/ /Alemanha). Desde o início de suas atividades até o momento de produção deste artigo, as vivências da parceria foram desenvolvidas no Clube de Campo do Sindicato dos Metalúrgicos, localizado no bairro Santa Felícia, no município de São Carlos, São Paulo, Brasil.

O VADL-MQF tem como objetivo geral a educação pelo e para o lazer de crianças e adolescentes de comunidades vulneráveis do citado município (Gonçalves Junior, 2017). Os/as participantes do projeto têm idade entre 7 e 17 anos e, em sua maioria, residem em bairros periféricos e empobrecidos de São Carlos. As atividades são desenvolvidas em dois dias da semana, contando com quatro atividades centrais. São elas: capoeira e fútbol callejero às terças-feiras; ciclismo e musicalização às quintas-feiras, sempre pela manhã e pela tarde no contraturno do período escolar dos/as participantes.

Gonçalves Junior (2017) comenta que as ações do projeto são suleadas ${ }^{5}$ pelo referencial da Motricidade Humana (Sérgio, 2003), da Fenomenologia Existencial (Merleau-Ponty, 2011), da Pedagogia Dialógica (Freire, 2001, 2005) e da Ecologia de Saberes (Santos e Meneses, 2009), dando atenção ao "sendo-uns-com-os-outros-ao-mundo" (Gonçalves Junior, 2017). Ser, portanto, como diz Freire, inconcluso e incompleto, que está sempre sendo, se fazendo e refazendo nas relações de intersubjetividade com os outros seres no pano de fundo do contexto do mundo, pois:

Consciente de que posso conhecer social e historicamente, sei também que o que sei não poderia escapar à continuidade histórica. O saber tem historicidade. Nunca é, está sempre sendo [...]. A história é tão vir-a-ser quanto nós [...], quanto o conhecimento

\footnotetext{
5 Trata-se de um neologismo que faz contraposição à ideologia contida na expressão "norteada", que subliminarmente alude ao hemisfério norte, ideologicamente apresentado como superior ao hemisfério sul; mais que isso, propõe que tenhamos como referência o hemisfério sul e epistemologias do Sul. Aprofundamentos sobre esta temática podem ser feitos nas leituras de Santos e Meneses (2009).
} 
que produzimos. [...] Seria impensável um mundo onde a experiência humana se desse fora da continuidade, quer dizer, fora da História. [...] Não podemos sobreviver à morte da história que, por nós feita, nos faz e refaz. (Freire, 2001: 18)

Em nossa práxis educativa salientamos, como Merleau-Ponty, nossa oposição à tradição cartesiana que

nos habituou a desprendermos do objeto: a atitude reflexiva purifica simultaneamente a noção comum do corpo e a da alma, definindo o corpo como uma soma de partes sem interior, e a alma como um ser inteiramente presente a si mesmo. (2011: 268)

Deste modo, nos afastamos de uma visão reducionista e de epistemologias mutiladoras que fragmentam o Ser, posto que o corpo não se move pela reunião de partes e na ignorância de si, mas irradiando de um si captado no pano de fundo do mundo, pois o corpo é o lugar de todo o diálogo que envolve eu-outrem-mundo. Compreensão também compartilhada por Sérgio (2003), ao se referir à Motricidade Humana como movimento intencional de transcendência que envolve práxis intersubjetiva e abertura radical à vida, ao ser mais.

A sistematização da dinâmica de trabalho do VADL-MQF junto a seus/ /suas participantes sugere a dialogicidade necessária para a emersão da ecologia de saberes (Santos e Meneses, 2009), na qual crianças e adolescentes são partícipes tanto nas ações quanto nas comunicações e trocas de saberes durante as vivências do projeto socioeducativo. Com efeito, o início das atividades de cada encontro é marcado pela roda inicial. Neste momento, com toda gente compondo um círculo, é empreendido um diálogo com vistas a acolher os/as participantes que são convidados/as a contar suas novidades, suas experiências vivenciadas nos dias que antecederam o encontro, tecerem comentários sobre seus mundo-vidas e compartilhar seus sentimentos (alegrias, tristezas, angústias, ansiedades, entre outros).

Logo após os diálogos da roda inicial, é desenvolvido o jogo de integração. A intencionalidade desta atividade, como o próprio nome sugere, é de integrar todos/as participantes de modo a estabelecer um clima de descontração, abertura e convite para as vivências e os diálogos conseguintes. Cumpre ressaltar que a eleição do jogo/da vivência é feita pelos/as próprios/as participantes através de um processo de votação e/ou consenso realizado no final do encontro anterior.

$\mathrm{Na}$ esteira do jogo de integração são desenvolvidas as atividades centrais, ou seja, atividades que foram eleitas por crianças, adolescentes e educadores/as para serem desenvolvidas em todos os encontros que ocorrem semanalmente. 
Desta forma, conforme dito anteriormente, no período de nossa inserção para a presente investigação foram desenvolvidas às terças-feiras a capoeira e o fútbol callejero, enquanto às quintas-feiras foram vivenciadas a musicalização e o ciclismo.

Marcando o encerramento de cada encontro, são realizadas as rodas finais. Nestas, com todos os participantes formando um novo círculo, são empreendidos diálogos para avaliação das (con)vivências, da comunicação e da troca de saberes suscitados durante os encontros e, também, para a realização do planejamento das atividades do(s) encontro(s) seguinte(s). Nas rodas iniciais e finais organizadas no contexto do VADL-MQF, o diálogo é tanto o meio que baliza o processo de interconhecimento (Santos e Meneses, 2009) quanto a qualidade da relação de estar-sendo-com-outrem-e-com-mundo.

Ficámos muito intrigados com a ressonância estabelecida entre a dinâmica do fútbol callejero com a perspectiva pedagógica que já era desenvolvida pelo VADL-MQF. Ambas estão alicerçadas nos horizontes da educação popular, cujo diálogo é o princípio fundante para o protagonismo dos/as participantes no processo de convivência para leitura da realidade, troca de saberes e de interconhecimento:

Desde o começo, "a metodologia" [do fútbol callejero] faz de seus participantes protagonistas, abrindo um espaço em que não jogam somente chutando uma bola, mas também propondo as regras do jogo e debatendo sobre seu resultado. Diferentemente do que ocorre no futebol convencional (e fazendo uma ponderação mais abrangente, diferentemente do que geralmente ocorre nas ações sociais pensadas para os jovens), o fútbol callejero é impensável sem a existência de participantes ativos, que transcendam o lugar de meros “jogadores" [e jogadoras] (Rossini et al., 2012: 114-115; tradução e grifos dos autores).

A identificação da sinergia entre ambas as práticas nos encorajou a propor e a incorporar o fútbol callejero junto às ações do VADL-MQF, culminando na presente sistematização de experiências que buscou uma compreensão acerca dos processos educativos decorrentes da prática do fútbol callejero desenvolvida no contexto do projeto socioeducativo. Passaremos, então, para a apresentação da trajetória metodológica, seguida pela análise dos dados que permitiram a identificação e comunicação dos nossos saberes.

\section{Trajetória metodológica: a postura fenomenológica e a sistematização de experiências}

Em nossa caminhada metodológica optámos pela postura fenomenológica (Merleau-Ponty, 2011; Levinas, 2005) em interface com a sistematização de 
experiências (Jara-Holliday, 2006), tendo como premissa a ética de investigar com outrem. Conforme Levinas (2005), não basta saber da existência de outrem é preciso ter outrem como critério, ou seja, firmar postura ética pelo respeito e reconhecimento da alteridade. Nesta esteira, também contribui Merleau-Ponty ao afirmar:

O mundo fenomenológico é não o ser puro, mas o sentido que transparece na intersecção de minhas experiências, e na intersecção de minhas experiências com aquelas do outro, pela engrenagem de uma nas outras; ele é portanto inseparável da subjetividade e da intersubjetividade que formam sua unidade pela retomada de minhas experiências passadas em minhas experiências presentes, da experiência do outro na minha. (2011: 18)

Nosso afastamento da neutralidade científica, da dicotomia e fragmentação entre sujeito-objeto-mundo, envolveu a práxis intersubjetiva ao pesquisar, no compartilhar da esperança e do sonho de transformação da realidade social em uma perspectiva suleada, requerendo aproximação intensa com este outrem de modo a possibilitar o estabelecimento de laços recíprocos de confiança, solidariedade e acolhimento. Para tal, foi fundamental nosso reconhecimento da "diversidade epistemológica do mundo, [...] a existência de uma pluralidade de formas de conhecimento além do conhecimento científico" (Santos, 2009: 45). Reconhecendo nossas fragilidades e nossos não-saberes, entendemos que estamos assumindo com humildade nossa ignorância, o que não nos coloca numa posição de imobilismo, mas, sim, nos move na busca por aquilo que até então nos foi negado em um exercício denominado por Santos de interconhecimento:

cruzam-se conhecimentos e, portanto, também ignorâncias. Não existe uma unidade de conhecimento, como não existe uma de ignorância. As formas de ignorância são tão heterogéneas e interdependentes quanto as formas de conhecimento. Dada esta interdependência, a aprendizagem de certos conhecimentos pode envolver o esquecimento de outros e, em última instância, a ignorância destes. [...] A utopia do interconhecimento é aprender outros conhecimentos sem esquecer os próprios. (2009: 47)

Este saber requereu nossa disposição para conviver próximos e engajados com os colaboradores da pesquisa, para nos colocarmos a serviço da comunidade de modo, inclusive, a possibilitar uma melhor compreensão da realidade que investigamos, sendo fundamental o processo de escuta atenta durante os espaços de diálogos (especialmente nas rodas iniciais e 
finais, bem como nos momentos de $1 .^{\circ}$ tempo e mediação). Para o exercício da escuta atenta, no processo de investigação, foi essencial uma inserção respeitosa ao contexto para aproximar-se dos/as participantes, para o estabelecimento da intersubjetividade, com o cuidado de não tornar objeto outrem. Portanto, a empatia e a alteridade surgiram como elementos centrais de nossa ação, já que é ela que permite o encontro da subjetividade com a intersubjetividade. Trata-se de sair de si mesmo e colocar-se no lugar de outrem, em solidariedade.

Quanto à sistematização de experiências, Jara-Holliday afirma que esta tem como premissa a própria participação na experiência, pois: "só podem sistematizar uma experiência aqueles que tenham tomado parte dela e que não é possível que uma pessoa totalmente alheia à experiência pretenda sistematizá-la” (2006: 79).

Sua origem remete ao sul geográfico que, neste caso na América Latina, está intrinsecamente ligada à necessidade de descrever, interpretar, compreender, significar e compartilhar processos educativos decorrentes de práticas de educação popular, conforme sinaliza Eckert (2009). Nesse contexto, surgiu a necessidade de sistematizar experiências para refletir sobre a história vivida de movimentos sociais, sobre seus avanços e retrocessos com vistas a comunicar e compartilhar os saberes emergentes de tais práticas. Nas palavras de Jara-Holliday:

Experiências significativas como a dos Sem Terra no Brasil, as Comunidades em Resistência da Guatemala, o Movimento Indígena Zapatista em Chiapas, são uma clara amostra das potencialidades que se encontram na prática social de nosso continente, cujos ensinamentos urgem processar e partilhar. (1998: 3; tradução dos autores)

Nossa inserção para a sistematização de experiências junto ao contexto do VADL-MQF ocorreu após aprovação da investigação pelo Comitê de Ética em Pesquisa em Seres Humanos pelo Parecer n. ${ }^{\circ}$ 15.565.644. Salientamos que, em atenção às premissas éticas, os nomes dos/as participantes do estudo foram substituídos por nomes fictícios escolhidos por eles/as, mantendo-se apenas os nomes dos investigadores/autores deste artigo. Os encontros destinados à prática do fútbol callejero ocorreram às terças-feiras, no período da tarde, em integração com as demais atividades desenvolvidas no citado projeto.

Para efeito de sistematização de experiências, os respectivos registros foram concretizados a partir da confecção de diários de campo, correspondentes ao período de nossa inserção, que ocorreu durante os meses de agosto a dezembro de 2016. Em relação aos diários de campo, Bogdan e Biklen (1994) 
anunciam que estes envolvem aspectos descritivos e reflexivos. Os aspectos descritivos dizem respeito a: retratos dos sujeitos (incluindo sua aparência, roupas, falas, ações); reconstruções dos diálogos (as conversas e os gestos); descrição do espaço físico (através de desenhos ou mesmo descrições); relatos de acontecimentos particulares (caso ocorram e sejam pertinentes); descrição das atividades (incluindo as atitudes dos/as participantes); comportamento do/a observador/a (considerando-se a si próprio, atitudes, suposições e tudo o que possa afetar a coleta dos dados). Já a porção reflexiva envolve: reflexões sobre o método; sobre conflitos e dilemas éticos; sobre os pontos de vista dos/as observadores/as.

Em nossa trajetória metodológica, procurámos assegurar a autenticidade dos registros. Neste intento, compôs a porção descritiva dos diários de campo a transcrição na íntegra das falas dos/as participantes. Estas descrições procuraram respeitar, representar e valorizar os modos de fala dos/ /as participantes, seus maneirismos, com seus vícios e figuras de linguagem. Para tanto, foram realizadas filmagens dos momentos destinados para diálogo empreendidos no contexto do VADL-MQF.

No movimento de ad-mirar os dados registrados em diário de campo, no esforço por "realizar a análise, síntese e interpretação crítica do processo" (Jara-Holliday, 2006: 88), realizámos o processo de análise inspirados em Martins e Bicudo, que propõem a redução fenomenológica:

como é impossível analisar um texto inteiro simultaneamente, torna-se necessário dividi-lo em unidades. [...] as unidades de significado são discriminações espontaneamente percebidas nas descrições dos sujeitos quando o pesquisador assume uma atitude psicológica e a certeza de que o texto é um exemplo do fenômeno pesquisado [...] As unidades de significado [...] também não estão prontas no texto. Existem somente em relação à atitude, disposição e perspectiva do pesquisador. (1989: 99)

Com tal procedimento de análise, após diversas leituras dos diários de campo (identificados com algarismos romanos em ordem crescente de coleta I, II, III, IV...), destacámos unidades de significado (identificadas com algarismos arábicos em ordem crescente de ocorrência 1, 2, 3, 4...), em movimento de busca da essência do fenômeno em estudo: processos educativos decorrentes de uma sistematização de experiência com a prática social do fútbol callejero.

Ao prosseguir a análise dos dados, fomos des-velando a articulação entre diferentes unidades de significados (provenientes de distintos participantes e de distintos diários de campo), as quais formaram convergências e/ou 
divergências, possibilitando a construção da categoria temática "Fútbol callejero é para ser mais!" Passaremos agora para sua apresentação e discussão.

\section{"Fútbol callejero é para ser mais!"}

Nesta investigação, atraiu-nos muita atenção a potencialidade que o fútbol callejero possui para a sua constante ressignificação e reinvenção atribuídas por aqueles/as que participavam de cada encontro. Cada jogo se configurou como um espaço-tempo singular de convivência, possibilitado pela sua dinâmica de estabelecimento de regras e acordos. Compreendemos que esta característica inventiva, inerente à própria dinâmica do fútbol callejero, oportunizou para os/as participantes do projeto socioeducativo o protagonismo, a (co)responsabilidade e o comprometimento na criação e transformação do jogo, de modo que tal prática tem possibilitado o aprendizado do "ser mais":

Daí a necessidade que se impõe de superar a situação opressora. Isto implica o reconhecimento crítico, a "razão" desta situação, para que, através de uma ação transformadora que incida sobre ela, se instaure uma outra, que possibilite aquela busca por ser mais. (Freire, 2005: 34; grifos dos autores)

Variadas manifestações auxiliaram na emersão desta categoria, e iniciamos por aquelas que permitiram a identificação da potencialidade dialógica (Freire, 2005) que o fútbol callejero lança a seus/suas participantes ancorado, de um lado, pelo referencial do projeto socioeducativo, de outro, pelos três pilares fundamentais do método fútbol callejero: respeito, cooperação e solidariedade (Rossini et al., 2012), promovendo humanização das relações, convidando seus/suas participantes ao exercício de um constante refletir e (re)inventar o jogo, de maneira a primordialmente acolher outrem, conforme expressam os participantes Melissa e Roberto, diante da pergunta do educador Maurício, no primeiro tempo do método fútbol callejero:

Maurício: Pessoal, [...] qual regra que vocês gostariam de propor?

Melissa: Acho que não excluir os menores na hora de jogar.

Maurício: E aí, como isso virou uma regra na hora de jogar [...] como é que a gente vai fazer isso no jogo?

Roberto: Tocando para eles.

Melissa: Tocar para todos. (VI-25) 6

\footnotetext{
${ }^{6}$ No caso da sigla "VI-25" que acompanha a citação destacada, leia-se "diário de campo VI unidade de significado 25”. Embora não seja possível apresentar como apêndice os diários de campo na íntegra, devido ao número de páginas disponíveis para a publicação deste artigo, nossa intencionalidade está em indicar a origem/localização do trecho e do diário citados.
} 
Neste cuidado com outrem, identificámos ações que implicaram em atitudes e gestos benfazejos, construindo uma convivência cuidadosa, segundo fala da participante Julha:

Maurício: Você quer sugerir regras?

Julha: Não pode dar carrinho.

Maurício: Hoje é importante, assim como nós fizemos na última terça que nós jogámos fútbol callejero, falar o porquê. Por que não pode dar carrinho?

Julha: Porque machuca. (III-7)

Em nossos registros em diários de campo também identificámos a criação de um espaço-tempo brincante, como dito por Quero-Quero:

Quero-Quero: Se bater na trave vale ponto.

Klevis: Quanto?

Quero-Quero: Um ponto.

Maurício: Um ponto. Mas por que você quer sugerir essa regra?

Quero-Quero: Porque é mais divertido. (III-8)

Esta asserção põe em destaque que, ao proporem regras para o jogo, os participantes puderam tornar a sua prática mais divertida, a seus gostos e interesses como vimos em Rossini et al. (2012), ao afirmar estas intencionalidades de Fabián Ferraro ao criar o fútbol callejero. Também podem auxiliar na potencialização da defesa de direitos e interesses e mesmo extrapolar o contexto do jogo, transformando a realidade concreta. Em um dos encontros, em que os/as participantes sugeriram jogarmos fútbol callejero na quadra de areia, os participantes Roberto e Vanessa também destacaram a alegria de jogar neste espaço e, ainda, Roberto comentou que, para além de tornar o jogo mais divertido, a criação coletiva das regras possibilita um jogo mais equilibrado:

Roberto: Eu gostei mais do fútbol callejero hoje. [...] Estava mais equilibrado. [...] Também a gente caiu bastante na areia.

Vanessa: Hoje o dia foi legal porque eu tomei um banho de areia! (VI-32)

A postura ética de respeito e reconhecimento da alteridade (Levinas, 2005), observando a intersecção das experiências suscitadas no ato de conviver com outrem e com o mundo, em pleno exercício de intersubjetividade (Merleau-Ponty, 2011) e da ecologia dos saberes (Santos e Meneses, 2009), foram observadas entre os pares participantes-participantes, 
participantes-educadores/as, bem como entre educadores/as-educadores/as, como identificado no registro a seguir, originário de diálogo entre o educador Maurício, mais experiente, e a educadora Mariana, que realizava o processo de mediação do fútbol callejero no projeto pela primeira vez:

Maurício: O desenvolvimento da mediação não é difícil, mas envolve alguma complexidade. Desde a dinâmica de anotação até à problematização dos eventos e atitudes ocorridas durante uma partida de fútbol callejero envolve saberes e experiências pedagógicas que auxiliam no processo dialógico para o estabelecimento de acordos e reflexão acerca das atitudes que ocorreram durante o 2. Tempo. Especialmente sendo sua primeira mediação, Mariana fique à vontade para pedir auxílios, [...] desde o modo de fazer as marcações dos pontos, até o como fazer a pergunta problematizadora. (III-12)

Em situação análoga, o educador Jhony compartilhou com os/as participantes do VADL-MQF sua experiência de desenvolver o fútbol callejero em contexto de apresentação de seminário em uma disciplina do curso de Educação Física na UFSCar, apontando para as diferentes manifestações que emergiram no contexto do seminário, quando relacionado com o projeto socioeducativo:

Jhony: Foi bem diferente [...] em relação a ser mais competitivo. [...] A cooperação fica muitas vezes de lado por causa da competição que eles têm entre eles. Às vezes eles esquecem de tocar, ou quando tocam é pra mesma pessoa. [...] Mas, eram solidários, isso depois do jogo, foram bem solidários. [...] Respeitaram as regras, e pelo tempo também que a gente tinha o jogo ficou um pouco mais [...] mais corrido. Mas deu pra mostrar um pouquinho o que é o fútbol callejero. Porque muitos lá não conheciam. (III-17)

Percebemos que a prática da dialogicidade é uma tônica entre todos/as do projeto. Como afirma Freire (2005), aprender a dizer sua palavra é fundamental para a construção da autonomia, bem como a incorporação dos pilares do fútbol callejero (solidariedade, respeito e cooperação), conforme segue na asserção do educador Maurício na roda de conversa final do projeto junto a todos/as educadores/as e participantes presentes: "Então vejam que vocês podem o tempo todo ser solidários uns com os outros quando compartilham saber. Uma sabedoria!" (VII-22).

Também encontrámos registros que comunicavam que o fútbol callejero foi posto em ecologia com outras práticas, na qual os/as participantes comunicavam seus saberes acerca da apropriação e transferência da lógica 
do fútbol callejero para outras práticas, conforme observamos na ocasião de diálogo entre o educador Maurício, que, após exemplificar tal possibilidade, problematizou com os/as participantes a possibilidade da realização do jogo $M y$ God à luz do método de tal dinâmica que propuseram:

Quero-Quero: Quando a bola estiver dentro do campo de quem está montando, poder pegá-la.

Maurício: Poder pegar? Vocês topam turma?

Nino: Não! [Respondeu de maneira bastante efusiva]

Maurício: Por que Nino?

Nino: Por causa que... Não pode entrar no campo que estão montando as latinhas.

Maurício: Mas ele [o Quero-Quero] está dizendo agora que seria um gesto solidário que a equipe de quem está montando a lata permitir que o adversário entre [na cancha do adversário]. Mas eu posso queimar o adversário? [Esta pergunta foi direcionada ao Quero-Quero, propositor da regra].. É só pra pegar a bola? Daí eu me afasto até a linha?

Quero-Quero: Sim [no sentido de que só poderia queimar o adversário somente após ultrapassar a linha].

Maurício: Olha... Achei legal hein?

Leão: Eu topo! [Disse o participante de maneira espontânea e com excitação, chegando a levantar do assento da cadeira] (V-4)

Em ocasião análoga, durante a realização de uma roda final o educador Maurício problematizou junto aos/as participantes a possibilidade de incorporação da lógica de avaliação dos pilares do fútbol callejero para o jogo Garrafobol, ${ }^{8}$ de tal modo que o participante Quero-Quero e a participante Julha apresentaram, em genuíno exercício de ecologia de saberes:

Maurício: Muito bem... É, "ceis" [entenda-se "vocês"] lembra que a gente tá vendo que nosso projeto pode ser como o fútbol callejero? Vocês acham que teve cooperação hoje?

[Todos/as os/as participantes responderam, em coro, "sim". Continuei na investigação...]

Maurício: Em que momento?

Quero-Quero: No Garrafobol.

Maurício: E como é que foi a cooperação no Garrafobol?

\footnotetext{
${ }^{7}$ Jogo com origem em Maputo (Moçambique), que na região sudeste do Brasil podemos identificá-lo como sendo uma variação do jogo de "queima" ou "queimada".

8 Jogo que em São Paulo (Brasil) recebe o nome de "queima" ou "queimada", no qual, em lugar de atingir o corpo do oponente, se busca atingir a garrafa descartável/plástica de cada participante do time oposto.
} 
Quero-Quero: Ajudando a proteger a garrafa do outro quando ele vai jogar a bola. Maurício: Ah... Uma salva de palmas pra ele... Porque a cooperação dentro do fútbol callejero é o que você faz para seu próprio parceiro. Pra quê?

Julha: Amigo... Pra ajudar uns aos outros. (VII-21)

\section{À guisa de novos horizontes: outros futebóis possíveis, outras motricida- des emergentes}

Ao optarmos nesta investigação pela postura fenomenológica em interface com a sistematização de experiências e as epistemologias do Sul, procurámos colocar nossos saberes e práticas científico-acadêmicas ao serviço da comunidade participante.

O fútbol callejero, compreendido como uma epistemologia do Sul, anuncia:

- Descolonização - O futebol moderno, do norte epistêmico, é gerenciado pela FIFA, a qual institui regras obrigatórias para competições locais, nacionais e internacionais; interfere no formato das competições de futebol nos distintos países, incluindo construções de estádios/arenas, e nas decisões políticas sobre acesso ou não de variados produtos nos espaços de jogos, interesses por vezes alheios às demandas das populações locais. O fútbol callejero, nascido e criado no Sul (originário da Argentina), visando desvincular-se da lógica gestora hierárquica impositiva, comercial e midiática da FIFA, desvincula-se da mesma, mantendo o princípio da autogestão (aqueles que o praticam, de modo situado, dialogam e organizam suas regras e o modo de prática) e a organicidade dos três pilares (respeito, cooperação e solidariedade). Sendo fundamentado como uma prática de educação popular, o fútbol callejero questiona a lógica de uma matriz de saber e poder, questiona a colonialidade, instaurando poder e saber construídos de modo compartilhado, do povo em suas práticas.

- Despatriarcalização - O futebol moderno preconiza a separação obrigatória de sexo em sua prática justificada por características anatomofuncionais. Diferentemente, no fútbol callejero, homens e mulheres, bem como pessoas mais habilidosas e menos habilidosas, são incluídos, jogam juntos/as na mesma equipe, com possibilidade de conformação das regras, favorecendo a participação justa dos/as participantes em equidade, alicerçada na convivência respeitosa, cooperativa e solidária - premissas do fútbol callejero.

- Descapitalização - O futebol à inglesa, ao separar praticantes por sexo e por habilidade de alto rendimento, decorrente do patriarcado, acaba por valorizar apenas um formato: o futebol jogado por homens, largamente difundido e comercializado nos meios de comunicação, tornando ausente o futebol praticado por mulheres e/ou populares. 
No fútbol callejero, o valor está na participação popular, de homens e mulheres, nos três tempos do jogo, acolhendo as demandas da população, acolhendo jovens das periferias urbanas, entendendo-os/as e incentivando-os/as ao protagonismo.

Consideramos que quando os/as participantes, por exemplo, criam regras (1. ${ }^{\mathrm{o}}$ tempo), desenvolvem um jogo que prescinde ao controle de terceiros/as (árbitro/a durante o $2{ }^{\circ}$ tempo) e que, ao final (no $3 .^{\circ}$ tempo), avaliam a qualidade das relações estabelecidas com outrem e também com os próprios acordos firmados previamente. O fútbol callejero instaura uma perspectiva inexorável de processos educativos de corresponsabilidade, autonomia e protagonismo de seus/suas participantes, favorecendo a práxis da humanização, de ser mais.

A dialogicidade, base de todo o projeto e destaque no 3 . $^{\circ}$ tempo (ou mediação) do método fútbol callejero, valorizou a fruição da alteridade, em que o encontro intersubjetivo face a face com outrem pôs em destaque nossa condição de coexistência ao mundo. Tal movimento emergiu, principalmente, de situações nas quais os/as participantes tiveram de refletir acerca de determinado evento - que no fútbol callejero pode ser uma jogada específica, uma palavra que expresse um desafeto, uma atitude agressiva, um ato benfazejo, uma ação acolhedora, entre outras possibilidades - tornando-se objeto de apreciação de toda gente envolvida no jogo.

À guisa de novos horizontes, des-velamos, com base na categoria construída "Fútbol callejero é para ser mais!", esta motricidade emergente, nascida e criada no Sul (metafórico e geográfico, originário da Argentina), com povos do Sul (crianças e adolescentes de comunidades vulneráveis da cidade de São Carlos, Brasil), prática que desde sua origem apresenta-se alheia aos interesses comerciais e epistêmicos do norte metafórico e geográfico, assim como outras motricidades historicamente invisibilizadas e tornadas ausentes, como outros futebóis, mas que vivem, lutam e resistem nas periferias populares das cidades, apontando para a concreta possibilidade de formação humana para ser mais, para o engajamento na/pela (trans)formação deste mundo que está aí em outro mundo possível: mais justo, bonito e solidário.

Revisto por Victor Ferreira

\section{Referências bibliográficas}

Artavia-Loría, Roberto (2008), Defensores del Chaco: o futuro construído por todos. Série Estudos de Caso. Santiago: Viva Trust. Consultado a 30.05.2017, em http://www. vivatrust.com/page/po-defensores-del-chaco-o-futuro-construido-por-todos. 
Belmonte, Maurício Mendes (2014), "Vivências em atividades diversificadas de lazer: processos educativos decorrentes de uma práxis dialógica em construção”. Dissertação de Mestrado em Educação, apresentada à Universidade Federal de São Carlos, São Carlos, São Paulo, Brasil.

Bogdan, Robert; Biklen, Sari Kinopp (1994), Investigação qualitativa em educação: uma introdução à teoria e aos métodos. Porto: Porto Editora.

Coon, Jeremy; Durbin, Paula (2013), "Fútbol callejero y cambio en el conurbado de Buenos Aires", Desarrollo de Base. Revista de la Fundacion Interamericana, 34, 11-21.

Eckert, Cordula (2009), Orientações para elaboração de experiências. Porto Alegre: EMATER-RS-ASCAR.

Freire, Paulo (2001), A sombra desta mangueira. São Paulo: Olho d'Água.

Freire, Paulo (2005), Pedagogia do oprimido. Rio de Janeiro: Paz e Terra [43. a ed.].

Galeano, Eduardo (2014), Futebol ao sol e à sombra. Porto Alegre: L\&PM.

Gonçalves Junior, Luiz (2017), "Plano de trabalho da parceria entre os projetos 'Vivências em Atividades Diversificadas de Lazer' (DEFMH/UFSCar) e 'Mais Que Futebol' (ADESM)”. São Carlos: Fundação de Apoio Institucional ao Desenvolvimento Científico e Tecnológico da Universidade Federal de São Carlos.

Gonçalves Junior, Luiz; Carmo, Clayton da Silva; Corrêa, Denise Aparecida (2015), "Cicloviagem, lazer e educação ambiental: processos educativos vivenciados na Serra da Canastra”, Revista Licere, 18(4), 173-208.

Grifi, Giampiero (1989), História da educação física e do esporte. Porto Alegre: Sagra/D.C. Luzzatto.

Jara-Holliday, Oscar (1998), “El aporte de la sistematización a la renovación teórico-prática de los movimientos sociales”. Consultado a 15.10.2013, em http://centroderecursos.alboan.org/sistematizacion/es/registros/5774-el-aporte-de-la.

Jara-Holliday, Oscar (2006), Para sistematizar experiências. Brasília: Ministério do Meio Ambiente [2. ${ }^{\mathrm{a}}$ ed.].

Levinas, Emmanuel (2005), Entre nós: ensaios sobre a alteridade. Petrópolis: Vozes [2. ${ }^{\mathrm{a}}$ ed.].

Martins, Joel; Bicudo, Maria Aparecida Viggiani (1989), Pesquisa qualitativa em psicologia: fundamentos e recursos básicos. São Paulo: EDUC - Editora da Pontifícia Universidade Católica de São Paulo.

Merleau-Ponty, Maurice (2011), Fenomenologia da percepção. São Paulo: Martins Fontes [4. ${ }^{\text {a }}$ ed.].

Nolasco, Carlos (2015), "Bola prá frente! Em busca de outro futebol”, in Boaventura de Sousa Santos; Teresa Cunha (orgs.), Atas do Colóquio Internacional "Epistemologias do Sul: aprendizagens globais Sul-Sul, Sul-Norte e Norte-Sul”, vol. III - Outras economias. Coimbra: Centro de Estudos Sociais, 491-503.

Oliveira, Maria Waldenez de; Silva, Petronilha Beatriz Gonçalves; Gonçalves Junior, Luiz; Montrone, Aida Victoria Garcia; Joly, Ilza Zenker Leme (2014), "Processos 
educativos em práticas sociais: reflexões teóricas e metodológicas sobre pesquisa educacional em espaços sociais”, in Maria Waldenez de Oliveira; Fabiana Rodrigues de Souza (orgs.), Processos educativos em práticas sociais: pesquisas em educação. São Carlos: EdUFSCar - Editora da Universidade Federal de São Carlos, 29-46.

Rossini, Luciano; Serrani, Esteban; Weibel, Matias; Wainfeld, Manuel (2012), Fútbol callejero: juventud, liderazgo y participación - Trayectorias juveniles en organizaciones sociales de América Latina. Buenos Aires: FUDe.

Sánchez, Leonel; Salermo, Juan (2012), "El fútbol callejero: un deporte inclusivo en Chos Malal, Provincia del Neuquén”, Revista EFDeportes, 17(175). Consultado a 24.05.2017, em http://www.efdeportes.com/efd175/el-futbol-callejero-en-chosmalal.htm.

Santos, Boaventura de Sousa (2002), "Para uma sociologia das ausências e uma sociologia das emergências", Revista Crítica de Ciências Sociais, 63, 237-280. Consultado a 24.05.2017, em https://journals.openedition.org/rccs/1285.

Santos, Boaventura de Sousa (2009), "Para além do pensamento abissal: das linhas globais a uma ecologia de saberes", in Boaventura de Sousa Santos; Maria Paula Meneses (orgs.), Epistemologias do Sul. Coimbra: CES/Almedina, 23-71.

Santos, Boaventura de Sousa; Meneses, Maria Paula (2009), "Introdução", in Boaventura de Sousa Santos; Maria Paula Meneses (orgs.), Epistemologias do Sul. Coimbra: CES/ /Almedina, 9-19.

Sérgio, Manuel (2003), Um corte epistemológico: da educação física à motricidade bumana. Lisboa: Instituto Piaget [2. ${ }^{\text {e }}$ d.].

Artigo recebido a 12.01.2018

Aprovado para publicação a 17.05.2018

\section{Maurício Mendes Belmonte}

Doutorando no Programa de Pós-Graduação em Educação, Universidade Federal de São Carlos Rodovia Washington Luís, Km 235, Jd. Monjolinho, São Carlos, CEP: 13.565-905, Caixa Postal: 676, São Paulo, Brasil

Contacto: mauriciobelmonte014@gmail.com

\section{Luiz Gonçalves Junior}

Departamento de Educação Física e Motricidade Humana, Universidade Federal de São Carlos Rodovia Washington Luís, Km 235, Jd. Monjolinho, São Carlos, CEP: 13.565-905, Caixa Postal: 676, São Paulo, Brasil

Contacto: luiz@ufscar.br 


\section{Fútbol Callejero: Born and Raised in the South}

The purpose of this article is to identify, describe and comprehend educational processes resulting from systematization of experiences with the social practices of fútbol callejero, developed in a social-educative project in a socio-economically vulnerable community. The methodological trajectory which we selected opted for a phenomenological posture in interface with systematization of experiences and employed ethics-based practices when conducting research with individuals. From the data analysis, the category "Fútbol callejero means being more!" emerged, revealing actions/attitudes expressing care for others, co-responsibility, autonomy and the protagonism of the participants. We then consider the need to search for new horizons in practices and "footballs" that have been historically invisible (absent motricities) but which live, fight, resist, and manifest themselves as emergent motricities in the outskirts of metropolitan areas.

Keywords: educational processes; epistemologies of the South; ethical values; popular education; street football.

\section{Fútbol callejero: né et créé dans le Sud}

Cet article a pour finalité d'identifier, de décrire et de comprendre des processus éducatifs découlant d'une systématisation de l'expérience acquise par la pratique sociale du fútbol callejero (football de rue), développé en un projet socioéducatif dans une communauté socio-économiquement vulnérable. Dans la trajectoire méthodologique, nous avons choisi l'attitude phénoménologique en interface avec la systématisation de l'expérience en ayant comme présupposé l'éthique de procéder à nos recherches avec autrui. L'analyse des données a permis de faire émerger la catégorie "Le football de rue, c'est être meilleur!”, révélant des actions/attitudes de souci à l'égard d'autrui, de coresponsabilité, d'autonomie, et de protagonisme des participant(e)s. Nous estimons qu'il est nécessaire d'ouvrir de nouveaux horizons à des pratiques et footballs historiquement escamotés (motricités absentes), qui vivent, luttent, résistent, se manifestent en tant que motricités émergentes dans les banlieues des grandes villes.

Mots-clés: éducation populaire; épistémologies du Sud; football de rue; processus éducatifs; valeurs éthiques. 